\title{
Los antecedentes anglosajones de la aliadofilia política de Luis Araquistáin ${ }^{*}$
}

Manuel Menéndez Alzamora

Universidad de Alicante

Fecha recepción 20.10.2014 / Fecha aceptación 06.04.2015

\section{Resumen}

La división entre aliadófilos y germanófilos en la España neutral que contempla el arranque de la Gran Guerra en agosto de 1914 es una división o fractura que se traslada a la opinión pública española a través de la prensa. Sin periódicos ni revistas que se hagan eco de las posiciones ideológicas en las que se ha dividido Europa, la opinión pública hubiera quedado sin el seguimiento directo y próximo del drama que estaba desgarrando Europa. La gran guerra dejó millones de muertos en las trincheras, pero junto al barro y la humedad de la línea de frente, la batalla se desarrollaba en otros frentes, uno fundamental fue el de la información $\gg$

\begin{abstract}
The division between the sympathisers of the Allies and the Germanophiles in neutral Spain at the start of the First World War in August 1914 was a split or fracture that was portrayed in Spanish public opinion through the press. Newspapers and magazines echoed the ideological positions that divided European public opinion with a direct and close monitoring of the drama that was destroying Europe. The Great War left millions dead in the trenches, but away from the mud and damp of the front lines, the battle also progressed on other fronts. One was critical information and propaganda, where the 'trenches' were $\gg$
\end{abstract}

\footnotetext{
* Este trabajo forma parte de las actividades del Proyecto I+D+I del Ministerio de Economía y Competitividad FFI2013-42443-R "Crisis y relectura del liberalismo en el período de entreguerras (1920-1938): las aportaciones de Walter Lippmann y José Ortega y Gasset”.
} 
y también el de la propaganda, su trinchera específica fueron las redacciones de los medios, en muchas ocasiones apoyadas y manipuladas por los servicios inteligencia puestos al servicio de cada bloque. En España la guerra tuvo un reflejo intenso en la prensa, el semanario España es quizá el medio más importante y uno de sus directores Luis Araquistáin uno de los grandes periodistas aliadófilos. El artículo trata de investigar las fases previas de la trayectoria de Luis Araquistáin centrándonos en sus artículos de 1911 en los que hay una primera incubación de su pensamiento político y su aliadofilia que recibe una influencia muy importante del socialismo fabiano.

\section{Palabras clave}

Aliados, Primera Guerra Mundial, Ideología, Prensa Española certain newsrooms, many of which were supported and manipulated by the intelligence services of the two blocks. In Spain the war was intensely reflected in the press: the weekly magazine España was the most important medium, and one of its directors, Luis Araquistáin, was one of the great journalists who sympathised with the Allies. This article aims to investigate the preliminary stages of Araquistáin's career as a journalist focusing on El Liberal (1911), where one can find the first incubation of his political thought and affinity with the Allies, which was very significantly influenced by Fabian socialism.

\section{Key words}

Allies, WWI, Ideology, Spanish Press 


\section{1.- Los orígenes intelectuales y políticos del joven Luis Araquistaín}

Luis Araquistáin es uno de los principales periodistas de la aliadofilia liberal española. Junto con Ramiro de Maeztu es el intelectual que más relación tiene con la órbita cultural anglosajona, ha ejercido la corresponsalía británica desde Londres y ahí se forja tanto su aliadofilia como buena parte de los principios estructurales de su pensamiento. En este artículo se pretende encuadrar las bases de la primera producción periodística de Araquistáin, un proceso de maduración sin el que no se entiende su posterior paso estelar por la dirección del semanario España en su fase más profundamente aliadófila.

Luis Araquistáin nació en Bárcena de Pie de Concha, en Santander, el 18 de junio de 1886, aunque él siempre se reclamó como vasco: «Soy medio vasco. Biológicamente, quizás más vasco que castellano. Toda mi raza paterna es vasca y he vivido muchos años en el país vasco. Durante una parte de mi niñez, sólo hablé vascuence. Mis raíces son vascas, pero mi cabeza es española. Antes que vasco soy español, y antes que español, soy hombre». ${ }^{1}$

De familia perteneciente a la pequeña burguesía, su primera vocación fue el sacerdocio a la que renunció por su incompatibilidad con el celibato. En Bilbao siguió estudios de marino y desarrolló prácticas marítimas, después dejó la profesión y emigró a Argentina, de allí se trasladó a varios países de Europa. En 1908 retoma a España y emprende su carrera como publicista en la península. Vida Galante acoge sus primeras colaboraciones. El Noticiero Bilbaíno y Las Noticias de Barcelona también dan a la luz esas primeras colaboraciones del joven periodista. Las colaboraciones adquieren mayor continuidad cuando su firma aparece en El Mundo, periódico madrileño financiado por Benigno Chavarri -personaje de las esferas monárquicas de Bilbao- al que llega Araquistáin recomendado por el intendente del frontón Euskalduna de Bilbao.

La Mañana nació en Madrid en diciembre de 1909, periódico de corta existencia que dejará de editarse a finales de marzo de 1910. Dirigido por Manuel Bueno la redacción reunió a jóvenes periodistas y políticos: Luis Bello, Luis Morote, Gregorio Martínez Sierra y Ramón Pérez de Ayala, entre otros. Araquistáin ejerció la crónica internacional casi a diario en una columna titulada «La voz del exterior». Marta Bizcarrondo expresa que «lo más destacable - de sus colaboraciones en La Mañana- es el intenso deslumbramiento que ejerce sobre él la evolución política inglesa, impulsada por un liberalismo dinámico. Araquistáin se presenta como un liberal a lo Lloyd George, abierto a unas reformas que le faciliten el apoyo de una clase obrera consciente de las ventajas generales de la coalición» ${ }^{2}$. Los comentarios harán referencia también a la política italiana o a las campañas «antiespañolas» tras la ejecución de Ferrer Guardia.

Tras el paso por La Mañana y El Mundo, Araquistáin se afianza en El Liberal donde redactó su columna «Desde Londres» ejerciendo la corresponsalía en la capital británica. Allí

1. L. Araquistáin, “¿Unión con Portugal o separatismo de España? El nacionalismo vasco-catalán”, 1945, [inédito].

2. M. Bizcarrondo, Araquistáin y la crisis socialista en la II República. "Leviatán" (1934-1936), Madrid, $1975,17$. 
coincide con Pérez de Ayala y con Ramiro de Maeztu. De Londres se trasladó a Alemania, desde donde firmó una nueva sección en El Liberal, «Desde Berlín». El 20 de agosto de 1911, Vida Socialista, la revista semanal del Partido Socialista, publicó un artículo de Generoso Plaza en el que se incluye al joven periodista como miembro del Partido Socialista.

Nuestro trabajo revisa la producción periodística de Araquistáin durante la corresponsalía londinense en 1911 caracterizada por el contacto y la asimilación del socialismo fabiano que intentaba una genuina convergencia de liberalismo y socialismo muy adaptable a los intereses de las burguesías medias -liberales y urbanas- con las que se intentaba abordar una reforma pragmática y una normalización de la vida democrática de España. En los artículos de La mañana está claramente apuntada esta dirección: «presentan -señala Bizcarrondo- a liberalismo y socialismo como soluciones complementarias de un problema nacional enfocado desde la perspectiva del reformismo burgués» ${ }^{3}$.

\section{2.- El esplendor del socialismo fabiano}

El fabianismo como corriente del socialismo inglés a finales del siglo XIX nace de la asociación que utiliza el nombre del general romano Fabio Cunatator por algo más que por la veneración del mundo latino. En efecto, si por algo transciende la labor del militar romano es por utilizar una estrategia basada en la previsión del ataque, en el debilitamiento del enemigo y en el permanente atosigamiento como claves del éxito.

En la primavera de 1884 se imprimen dos mil folletos del primer texto fabiano: «¿Por qué hay tantos pobres?» y queda aglutinado el núcleo fundacional de la sociedad formado por Sydney Webb, Sydney Olivier, Graham Wallas y George Bernard Shaw. El sentido filantrópico de los primeros fabianos deriva de la constatación de la situación en la que subsistían la parte menos favorecida de los obreros ingleses: fluctuación de los salarios y los precios, trabajo estacional, malas condiciones laborales, empleo de menores... Mas esta constatación adquiere ciertos visos de cientificidad al ser fruto de las primeras investigaciones sociales en las que empiezan a aplicarse técnicas estadísticas. Paradigmática resulta en este sentido Life and Labour of the People in London de Charles Booth, un análisis que conduce a la «aritmética del infortunio» y nos remite a una crítica de los aspectos más desalentadores del liberalismo victoriano en clave casi utilitarista ${ }^{4}$.

Sobre este estado de las cosas se articula la respuesta fabiana que recogerá las excelencias del estratega que le da nombre para proponer un reformismo de tintes socializantes claramente desmarcado de cualquier programa ortodoxo.

La nueva propuesta de socialismo se desdecía como marxista al no negar el capitalismo y el camino sin retorno hacia el que supuestamente avanzaba; al tiempo que valoraba como

\footnotetext{
3. Bizcarrondo, op. cit., 19.

4. Véase, J. Stevenson, "De la filantropía al fabianismo", VV.AA. Ensayos fabianos sobre pensamiento socialista, Madrid, 1988, 36.
} 
positivos tanto su predisposición al avance tecnológico como su éxito productivo ${ }^{5}$. En el mismo orden de cosas George Bernard Shaw, prohombre fabiano, siempre equiparaba la libertad de competencia y la libertad individual a otras libertades, como las de palabra o la de prensa ${ }^{6}$.

La solución se encaminaba hacia un aumento de la intervención del Estado en todos los órdenes acompañado de una vuelta de tuerca en la democratización de sus instituciones. Desde el problema de la vivienda a la cuestión agraria, o desde el trabajo de los menores a la educación de los obreros, los fabianos empiezan a especular en alternativas políticas en las que el intervencionismo estatal fraguaba en un marco de respeto al sistema de libre mercado. De esta manera los procesos de transformación en la sociedad industrial británica vendrían presididos por el principio del cambio gradual. El olvido de las estridencias radicales y el sentido contemporizador marcaban el ritmo de la «penetración pacífica» en el sistema en el que los intelectuales tenían un papel de agentes de primera fila.

La corresponsalía de Araquistáin en Londres lo pone en contacto con esta nueva onda política, en un proceso paralelo al vivido por Ramiro de Maeztu. Tanto uno como otro serán los protagonistas básicos de la propagación de un liberalismo socializante de nuevo cuño que tendrá un papel fundamental a la hora de modelar las primeras formas ideológicas de la Generación del 14.

\section{3.- La impronta política del fabianismo y el ejercicio del periodismo}

¿En qué nuevas coordenadas podemos situar el pensamiento fabiano que Araquistáin empieza a absorber en 1909? Los textos del joven periodista dejan traslucir, mezclados con opiniones literarias, críticas teatrales o el simple comentario sorprendido de la vida cotidiana londinense, algunos de los pilares básicos en los que se apoya esta nueva manera de enfrentarse a las cosas.

Si de alguna manera queda caracterizada esta etapa es por el deslumbramiento que la figura y la política de Lloyd George causa a nuestro periodista. El político liberal británico será el agente de diversos cambios y propuestas de tinte socializador que puntualmente merecerán la columna elogiosa de Araquistáin. Así, el proyecto de ley que ampliaba la cobertura de los servicios médicos es catalogado como un profundo avance frente a los intereses económicos de los médicos que están en inversa relación a la salud de su clientela ${ }^{7}$. El proyecto se dividía en dos partes, la primera dedicada al seguro contra la enfermedad y la invalidez, y la segunda dedicada al seguro contra la desocupación. En ambos casos se ampliaba el anterior marco de protección y se articulaban tres fuentes de financiación: los patronos, los obreros y

5. Véase, E. Durbin, “Socialismo fabiano y ciencia económica”, VV.AA. Ensayos fabianos sobre pensamiento socialista, loc. cit., 67.

6. Véase, Durbin, loc. cit., 68.

7. Véase, L. Araquistáin, “Nacionalización de los médicos”, El Liberal, Madrid, 5 de junio de 1911, 3. 
el propio Estado. Ante tan planificado despliegue, nuestro periodista califica a Lloyd George como «el santo civil más grande de nuestra época» ${ }^{8}$.

Araquistáin se congratula de que «ya no queda resquicio en la vida del ciudadano inglés que se escape de la acción protectora del Estado» y que por tanto, ahora, "ya no le preocupará el problema de la libertad de conciencia, ni el problema de la satisfacción de las necesidades económicas más perentorias. Su espíritu podrá elevarse libremente, rotas las cadenas de toda sujeción mental o material, a las formas más altas del arte y de la ciencia» ${ }^{9}$. Gracias a esta reforma, Lloyd George es el hombre que sabe recoger «los anhelos ideales del liberalismo para transformarlos en hechos tan tangibles y tan sublimes» ${ }^{10}$.

Un numeroso grupo de parlamentarios envía al gobierno en el verano de 1910 una memoria para que retome algunas medidas económicas y tributarias paralizadas en primera instancia en la Cámara Alta. El grupo de medidas lleva el inconfundible sello de Lloyd George y sus objetivos giran en torno a la carga fiscal sobre el aumento del valor de los solares, un aumento «debido al desarrollo comercial e industrial de las ciudades, debe devolverse a la comunidad (...) $»^{11}$ : la medida, que según Araquistáin conecta con el pensamiento utilitarista de Stuart Mill, nos proporciona un nuevo ejemplo de la fe ciega que nuestro corresponsal prodiga hacia todas y cada una de las decisiones del político británico.

La política de acción social que protagoniza Lloyd George necesita indudablemente de buenos recursos económicos. Aquí comienza la segunda parte del problema. Araquistáin elogia el sentido pacifista del ministro inglés que le induce a condenar severamente el gasto militar que «hace detener el avance reformista del liberalismo» ${ }^{12}$ al tratarse de una partida importante en los presupuestos. Ahora bien, las alternativas del político liberal inglés le conducen a gravar fiscalmente con severidad a determinados grupos sociales: «¿Y cómo se va a arreglar este hombre para obtener en un año 5.000 millones de pesetas? Pues siguiendo el gran principio liberal de imponer tributos a aquellos que puedan soportarlos (...). La bolsa de los millonarios ingleses es la región que ha elegido Lloyd George para coger su botín» ${ }^{13}$. Este aumento de la recaudación tributaria se reclamará por determinados sectores políticos para mejorar las dotaciones presupuestarias del ejército o para la acción social: Araquistáin elogia la maestría del ministro inglés para capear intereses tan contrapuestos, «es un infatigable mago, que no cesa de sorprender al mundo con su prodigiosa capacidad de hacendista liberal» ${ }^{14}$.

Las costosas reformas de Lloyd George encontraron su máximo obstáculo en la Cámara Alta que respondía con severidad ante cualquier modificación de la política tributaria. Choque de intereses políticos que fue hábilmente utilizado por el propio ejecutivo al saldarse

8. L. Araquistáin, "Pensiones para enfermos”, El Liberal, Madrid, 16 de mayo de 1911, 1.

9. L. Araquistáin, "El individuo y el Estado. Visión de lo futuro", El Liberal, Madrid, 14 de abril de 1911, 1.

10. L. Araquistáin, “Génesis de una ley”, El Liberal, Madrid, 12 de mayo de 1911, 1.

11. L. Araquistáin, “Socialización. La obra de Lloyd George”, El Liberal, Madrid, 14 de agosto de 1910, 1.

12. L. Araquistáin, “Guerra en la paz”, El Liberal, Madrid, 10 de julio de 1910, 3.

13. L. Araquistáin, "El liberalismo económico”, El Liberal, Madrid, 6 de julio de 1910, 1.

14. L. Araquistáin, “El impuesto de utilidades”, El Liberal, Madrid, 6 de enero de 1911, 1. 
con la aprobación en agosto de 1911 de una ley que restringía severa, aunque no totalmente, la capacidad de veto que los lores tenían sobre lo legislado por la Cámara de los Comunes ${ }^{15}$.

En la polémica, Araquistáin entenderá el conflicto como un cuestionamiento de las bases profundas de la democracia, «el pueblo inglés está democratizado en su gran mayoría, sabe o presiente donde reside la soberanía de la nación y tiene clara conciencia de que los destinos de las oligarquías y, en general, los destinos del Estado, dependen de su exclusiva voluntad $»^{16}$. Desde el punto de vista democrático, una segunda cámara «restringe la obra legislativa de los que encarnan la representación directa del pueblo y, en consecuencia, es antidemocrática; y una segunda Cámara constituida por elección popular, se identifica en la de los Diputados, y, por lo tanto, sobra» ${ }^{17}$.

El objeto de la acción fabiana es penetrar en los resortes de Estado para hacer más eficaz la labor social. En este sentido, Araquistáin proclama la necesidad de que la Administración amortice limpiamente sus deudas al tiempo que sea capaz de obtener rentabilidades que amplíen el margen de acción de los servicios públicos. El centro de este difícil equilibrio lo hace depender de la "norma de conducta" de los funcionarios y los administradores ${ }^{18}$, un claro apunte de las trazas éticas que tan importante papel desempeñan en todo el pensamiento fabiano.

Esta fuerte carga de contenido moral que siempre envuelve el discurso fabiano la extiende nuestro periodista a diversas facetas de la vida. Así, no duda en elogiar la creación de una fundación dedicada o remunerar a aquellos que arriesgan o pierden sus vidas por salvar al prójimo ${ }^{19}$, o en informarnos de la existencia en Londres de más de veinte sociedades dedicadas a la protección de niños, lo que le da pie para recalcar que «un pueblo que sabe proteger su infancia contra la brutalidad, la miseria y la ignorancia es, sin duda, un pueblo que conoce el arte de formar buenos ciudadanos» ${ }^{20}$.

Donde quizá se descubre la huella de un estricto sentido moralizante es en sus propuestas de educación sexual para jóvenes y adolescentes. Aquí surge, de repente, la moralidad de católica de su juventud primera. En este sentido propone trasladar el modelo británico de implantación del deporte en la escuela dado que

«el resultado, a más de su desarrollo físico, consiste en que el instinto sexual tarda en despertarse, y es que los muchachos ingleses están libres de este trágico periodo de aberración por que atraviesa la adolescencia española, debido (...), sobre todo, a la falta de actividad física que distraiga la viciada imaginación y conserve adormecido el sexo (...); mientras los muchachos ingleses, con sus juegos atléticos, están aletargados sexualmente y pueden preparar los cimientos para su obra científica del mañana, los muchachos españoles, por falta de juegos atléticos y

15. Véase, L. Araquistáin, "La crisis inglesa”, El Liberal, Madrid, 9 de agosto de 1911, 1; y L. Araquistáin, "La derrota de los lores", El Liberal, Madrid, 16 de agosto de 1911, 1.

16. L. Araquistáin, “Democracia y oligarquía”, El Liberal, Madrid, 27 de febrero de 1911, 1.

17. L. Araquistáin, “¿Una o dos cámaras?”, El Liberal, Madrid, 9 de marzo de 1911, 2.

18. Véase, L. Araquistáin, "Moral de los servicios públicos”, El Liberal, Madrid, 24 de abril de 1911, 1.

19. Véase, L. Araquistáin, "El cultivo del heroísmo", El Liberal, Madrid, 2 de marzo de 1911, 2.

20. L. Araquistáin, “El amor a los niños”, El Liberal, Madrid, 30 de abril de 1911, 2. 
cuidado en los padres y maestros, no construyen más cimiento que el de su propia ruina física y, por tanto, también moral» ${ }^{21}$.

Ya desde los años veinte y treinta algunos círculos owenistas habían comprobado como una política demasiado experimental y radical en materia sexual chocaba con los modelos de comportamiento de los sectores sociales en los que se buscaba proyección ideológica ${ }^{22}$. Se abría una corriente que reclamaba la necesidad de separar los elementos políticos de un programa de los componentes relativos a una visión antropológica más amplia entre los que se incluían las relaciones entre sexo, cultura y naturaleza. B. Shaw se mostrará reiteradamente partidario de eliminar los elementos «sensuales» y «voluptuosos» de cualquier experiencia política y los Webb desaprobarán la «promiscuidad sexual» en la Unión Soviética de los años treinta como algo opuesto a la ética de la comunidad ${ }^{23}$.

Desde estos contornos moralizantes, el fabianismo muestra su núcleo duro en el terreno ideológico cuando se desmarca de otras posiciones socialistas más ortodoxas. Araquistáin se apoya en la publicación del libro de Ramsey Macdonald, El movimiento socialista, para dar luz a estas diferencias: la revolución no puede traer el socialismo sino que este deriva de un proceso orgánico de transformación social, «las verdaderas reformas suelen estar detrás de los Parlamentos, no detrás de las barricadas» ${ }^{24}$; aquí radica su sentido antimarxiano y su contenido liberal, la transformación se hace desde el propio sistema capitalista y mediante los mecanismos que este ha legitimado. Por ello Araquistáin pregona de esta nueva orientación «su naturaleza orgánica, interna, evolutiva, no modificable en un momento revolucionario, sino en una serie de momentos con el auxilio de la ley, que sólo puede ganarse con la agitación intelectual del pueblo, con la divulgación de los problemas nacionales, sobre todo en las regiones agrícolas, y con la organización en torno de ideas y no de hombres» ${ }^{25}$.

El fabianismo no abandona ciertos rasgos muy marcados de colectivismo, el propio Araquistáin se hace permanente eco de ellos cuando en clave psicologista cree ver como causa de muchos suicidios «el error de la inteligencia, según el cual la mayoría de los hombres ambicionan acumular más riqueza de la que necesitan $»^{26}$, lo que remite a la cuestión de fondo: la preferencia del mundo material sobre el intelectual que tienen los individuos. En otro momento critica la nueva ley de propiedad intelectual británica porque extiende los derechos de autor, una vez muerto, a los herederos, con lo que se beneficia a la familia en detrimento de la sociedad ${ }^{27}$. De manera todavía más ingenua se planteará «¿hasta qué extremo es legítima la propiedad individual en obras de arte? (...) ¿en dónde concluye la propiedad individual y

21. L. Araquistáin, "Los bárbaros del norte", El Liberal, Madrid, 28 de abril de 1911, 2.

22. Véase, J. Weeks, "Los fabianos y la utopía", VV.AA. Ensayos fabianos sobre pensamiento socialista, loc. cit., 111.

23. Véase, Weeks, loc. cit., 119.

24. L. Araquistáin, “Incomprensión del socialismo", El Liberal, Madrid, 22 de abril de 1911, 2.

25. Araquistáin, loc. cit., 2.

26. L. Araquistáin, "El suicidio y la civilización", El Liberal, Madrid, 27 de marzo de 1911, 1.

27. Véase, L. Araquistáin, "La propiedad literaria", El Liberal, Madrid, 20 de abril de 1911, 2. 
comienza la nacional en materias artísticas? $»^{28}$. Más sujeto a la realidad social de la Inglaterra que le tocó vivir, Araquistáin cargará de nuevo sobre el tema de la colectivización al mostrar la bonanza del proyecto de nacionalización de la compañía británica de teléfonos. En cualquier caso, y siguiendo el patrón fabiano, se trata de un colectivismo guiado por la Administración liberal ${ }^{29}$.

La acción interventora del Estado se traslada del socialismo fabiano a la propia percepción de Araquistáin que afirma: «El fin es que las condiciones de la vida de cada individuo estén enteramente aseguradas por el Estado (...). Sólo entonces se hallarán todos los hombres sobre idéntica base de condiciones para desenvolver libremente su personalidad». El principio liberal queda remarcado al coincidir con Hobhouse que «después de rechazar el socialismo mecánico de los historicistas y el burocrático de algunos utopistas, enlaza la corriente de lo que él llama socialismo liberal con lo que él llama también liberalismo económico» ${ }^{30}$.

La acción del Estado se completa con una atención a lo que en sus textos se suele englobar bajo el concepto de «máximo desarrollo de la personalidad», se trata de que esa acción protectora del Estado genere unas condiciones de igualdad a partir de las cuales los ciudadanos puedan desarrollar sus capacidades, aquí radica la auténtica «conquista de la substancia liberal» ${ }^{31}$.

\section{4.- La mirada anglosajona sobre ciertas constantes generacionales: elitismo, pedagogía política y europeísmo}

En esta mixtura de principios liberales aplicados sobre conceptos socializadores despeñan un papel fundamental las élites. El concepto hace referencia a aquellos grupos más capacitados -técnica y culturalmente- en los que el fabianismo confiaba la dura tarea inicial de «despertar» a las masas inactivas:

«Los hombres que llevan el mundo en la actualidad, no son las mayorías que obran por interés personal, sino unas pequeñas minorías que inventan, crean y practican por santo desinterés. Estas minorías son de todos los tiempos y de todos los lugares. Estas minorías son cada vez mayores, conforme las condiciones del desarrollo de la personalidad humana son menos desiguales para todos. (..), ¿no hay derecho a esperar que aumenten las minorías, que sólo actúan por estímulos puros del espíritu, y que, por lo tanto, sea más intenso el progreso externo e interno de las sociedades humanas?» ${ }^{32}$.

El papel de reactivación asignado en primera instancia al carácter filantrópico de estos grupos más avanzados conecta con el sentido aristocratizante que rodeaba a muchos de los

28. L. Araquistáin, “Molienda de millones”, El Liberal, Madrid, 19 de marzo de 1911, 2.

29. Véase, L. Araquistáin, "Nueva nacionalización”, El Liberal, Madrid, 25 de junio de 1911, 3.

30. L. Araquistáin, "La línea del liberalismo", El Liberal, Madrid, 19 de junio de 1911, 2.

31. L. Araquistáin, “Guerra de lenguas”, El Liberal, Madrid, 9 de julio de 1911, 1.

32. Araquistáin, “Nueva nacionalización”, loc. cit., 3. 
planteamientos fabianos. La tarea de modernización y racionalización administrativa de un Estado tan cargado de competencias debía de recaer en personas cualificadas. Este sentido elitizante que los fabianos ya hacían notar en el estricto ámbito burocrático cobraba una nueva dimensión cuando se trataba de perfilar la figura de un nuevo intelectual al que se colocaba en la avanzada de todo proceso transformador. Para Araquistáin resulta un modelo la figura de Bernard Shaw, quien «con su labor de periodista, primero; con sus discursos de la Sociedad Fabiana, más tarde, y con sus comedias, después, ha sido uno de los hombres que más han estimulado el progreso político y artístico -musical, pictórico y dramático- de Inglaterra en estos últimos treinta años» ${ }^{33}$. Esta su visión del intelectual cobra matices de clara ingenuidad cuando, por ejemplo, denuncia que en España

«los poetas no se han despertado aún a la vida objetiva. Viven contentos con sus torres de marfil, sus princesas tristes y sus rayos de luna. Siendo España uno de los países más trágicos del globo, los poetas no ven en torno de sí más que suavidades, (...). En estas circunstancias, un poeta que recogiera lo universal, lo europeo, frente a lo particular y africano, ¿no sería en España un fecundo instrumento de agitación y renovación?» ${ }^{34}$.

Luis Olariaga intervendrá en la polémica y reclamará no solamente la posibilidad de que el arte y la cultura tengan un valor social sino que esta posibilidad debe convertirse en deber. Araquistáin especifica y afirma que en una primera instancia el arte puede, además de su sentido exclusivamente estético, tener una función moral de tal manera que «determine estados dinámicos (...), que nos mueva a obrar, a ser mejores, a combatir el mal» ${ }^{35}$. Esta etapa llega a su término cuando gracias a la «acción coercitiva de la ley» y la «acción constructiva de la enseñanza», los hombres abandonen su individualismo y piensen en el interés común, en este momento «la moral habrá cumplido su misión y el Arte y la Ciencia serán actividades independientes» ${ }^{36}$.

Se perfilan del anterior discurso dos instrumentos que cobran singular importancia en la nueva tarea de transformación social y que forman parte del núcleo duro de la propuesta política de la Generación del 14: la prensa y la educación. El fabianismo concede un importante margen de confianza a la acción de la prensa sobre la sociedad, «el periodismo es un poderoso instrumento de gobierno liberal» ${ }^{37}$ afirma tajantemente Araquistáin. Se trata de un medio de educación que sirve de regulador social al sanear la vida pública: reclama la participación de los ciudadanos en la prensa, en lo que denomina «intervencionismo público», para de esta manera excitar la «veracidad y la cultura» de quienes escriben en prensa, así como para desenmascarar a «hombres provistos a lo sumo de una pseudo-

\footnotetext{
33. L. Araquistáin, “La nueva generación”, El Liberal, Madrid, 26 de abril de 1911, 2.

34. L. Araquistáin, "El poeta y el hombre”, El Liberal, Madrid, 15 de julio de 1911, 2.

35. L. Araquistáin, “Arte y moral”, El Liberal, Madrid, 20 de agosto de 1911, 2.

36. Araquistáin, loc. cit., 2.

37. L. Araquistáin, "Naturaleza del periodismo", El Liberal, Madrid, 19 de septiembre de 1910, 1.
} 
cultura $»^{38}$. A raíz del atosigamiento de toda la prensa británica hacia el ejecutivo, Araquistáin intenta descubrir la esencias profundas de un nueva manera de entender la libertad de prensa en donde «no hay periódicos que se venden por un puñado de dinero hoy a un gobierno, mañana al opuesto, a condición de defenderles, aun atropellando la verdad y el derecho (...). La vida de los periódicos ingleses tiene sus raíces en el pueblo; este hecho es condición y obligación de su existencia» ${ }^{39}$.

La educación se convierte en el segundo pilar que sostiene la acción reformadora. En Araquistáin los problemas pedagógicos están muy relacionados con su defensa del mundo rural: «La agricultura debe ser uno de los puntos fundamentales de todo programa político» ${ }^{40}$. Así, el éxodo rural se observa como una amenaza cada vez más real y se vincula a una educación defectuosa que transmite una imagen fantasiosa y encantada del mundo urbano. Por contra, una educación "perfecta», derivada del fomento de las escuelas rurales, paraliza la emigración campesina ${ }^{41}$. Incluso se atreve a dar un paso más: la repoblación rural: «Una buena política consistiría en encauzar hacia al campo el exceso de población de las ciudades, en vez de permitir que este exceso abandone el país con rumbo a mejores tierras. Pero esta política es imposible si no se resuelve primero el problema agrario» ${ }^{42}$. Mientras que la educación en las ciudades de aquellos que posteriormente van a continuar sus estudios en la universidad parece un flanco cubierto, queda por abordar la formación de quienes tienen un futuro como agricultores o como obreros, en este ámbito es en el que se propugna un nuevo modelo de escuela que debería proporcionar «una educación general preparatoria para todos los oficios» ${ }^{43}$.

Dos nuevas facetas acompañan, en otro orden de cosas, la configuración del pensamiento de Luis Araquistáin como intelectual fabiano: su postura ante el papel del ejército y el sentimiento europeísta. Las radicales posturas que el periodista cántabro mantendrá una vez desencadenada la Gran Guerra son percibibles en el periodo de la corresponsalía británica aunque ciertamente con un sentido bien diferente. Ahora se encuentra instalado en un pacifismo que le hace criticar con vehemencia cualquier aumento de las partidas militares de los presupuestos británicos y sospecha que los rumores que apuntan la existencia de preparativos para una invasión alemana de Inglaterra -depositados en la opinión pública a través de noticias alarmantes: espías alemanes, globos que sobrevuelan la isla...- no son más que un producto de la prensa más corrupta y degradada. El sustento teórico de este convencimiento antimilitar le viene dado por una novedad editorial -La gran ilusión de Norman Angell- que teoriza sobre cuestiones como la imposibilidad del poder militar para proporcionar benefi-

38. L. Araquistáin, “¿Cuánto cuesta vivir?”, El Liberal, Madrid, 31 de agosto de 1910, 2.

39. L. Araquistáin, "La crítica periodística”, El Liberal, Madrid, 15 de abril de 1911, 3.

40. L. Araquistáin, “El retorno a la tierra”, El Liberal, Madrid, 29 de enero de 1911, 2.

41. Véase, L. Araquistáin, “La enseñanza en las aldeas”, El Liberal, Madrid, 2 de enero de 1911, 1.

42. L. Araquistáin, “La emigración y la tierra”, El Liberal, Madrid, 10 de mayo de 1911, 2.

43. L. Araquistáin, "Una escuela para hacer obreros”, El Liberal, Madrid, 24 de julio de 1911, 1.

Revista de Historiografía 24, 2016, pp. 57-70 
cios materiales a quien lo posee o sobre la guerra como mal necesario debido a la inmutable por naturaleza «psicología guerrera del hombre» ${ }^{44}$.

Araquistáin considera que el sentido pacifista que propone como modelo de relación entre las naciones es algo asumido por todas las sociedades y su realización práctica depende exclusivamente del rango que haya alcanzado su democracia: «Si los pueblos no han impuesto aún el desarme de las naciones respectivas, no es por falta de convencimiento de que la razón económica de la guerra es falsa, sino porque todavía no se ha apoderado bien de ellos la idea democrática» ${ }^{45}$. Respecto a la fundamentación última de la guerra plantea un singular conflicto de intereses que remite al carácter sui géneris de su socialismo: «Hoy la guerra representa, más que un conflicto de naciones, un conflicto de clases, de fracciones sociales; por una parte, la fracción social compuesta de trabajadores y de capitalistas, que ven en la paz una condición necesaria (...), y por otra, la fracción de los que anhelan la guerra para satisfacción de sus bastardos intereses, de sus odios absurdos o de sus errores lamentables ${ }^{46}$. Con fines igualitarios dará la bienvenida a la sustitución de la redención en metálico por el servicio militar obligatorio, aunque no se le escape afirmar que lo deseable sería un servicio militar voluntario ${ }^{47}$.

Respecto al segundo elemento, merece la pena destacar el acendrado europeísmo latente en el discurso del periodista. Volvemos hacia la recuperación de la idea de Europa que tan claramente habían interpretado Costa o Unamuno y heredan sus compañeros generacionales. A este último reprocha su ensimismamiento casticista: "Algunos han creído que Europa era sólo el progreso mecánico y se han opuesto a él con una filosofía africanista; tal, el Sr. Unamuno. Otros, como el buen Sr. Cejador, han creído que Europa es una especie de droguería intelectual, (...) y han ensalzado las ventajas de la medicina casera ${ }^{48}$. Frente a este desesperanzado panorama en el que el concepto «europeísmo» ha perdido su contenido y suena a palabra falsa con la que ensalzar ora con ingenua ignorancia ora con cínica adulación. Frente a esta falsificación, Araquistáin impone un restablecimiento de la dignidad del término y reclama un nuevo ideal europeo como «síntesis de todas las conquistas de la ciencia, de la moral y del arte que ha realizado el espíritu humano en estos últimos cuatro o cinco siglos» ${ }^{49}$. Europa queda remarcada como meta ideal cuando afirma que «viajar por Europa es, para un español, aprender en teoría la historia de los errores de la historia de España $»^{50}$.

Esta visión de lo europeo contrasta rápidamente con la ácida crítica que tanto Araquistáin como su propia generación, «los del 14», dedican a los aspectos de la vida social en los que creen observar la pervivencia de las costumbres más tétricas. La tauromaquia y el mundo que la rodea es foco de atención como ejemplo y manifestación profunda de la España negra.

44. Véase, L. Araquistáin, "La tragedia de la paz", El Liberal, Madrid, 16 de marzo de 1911, 2; y "Los fundamentos de la guerra”, El Liberal, Madrid, 18 de marzo de 1911, 2.

45. L. Araquistáin, "El pueblo y la guerra", El Liberal, Madrid, 22 de marzo de 1911, 1.

46. L. Araquistáin, "Una nueva internacional", El Liberal, Madrid, 5 de septiembre de 1911, 1.

47. Véase, L. Araquistáin, "El servicio voluntario”, El Liberal, Madrid, 4 de abril de 1911, 2.

48. L. Araquistáin, "Europa y nuestros intérpretes”, El Liberal, Madrid, 26 de mayo de 1911, 3.

49. Araquistáin, loc. cit., 3.

50. L. Araquistáin, “Amberes”, El Liberal, Madrid, 1 de julio de 1911, 3. 
Nuestro periodista se alarma cuando descubre que lo que en años no han conseguido ni Galdós, ni Menéndez Pelayo, ni Unamuno, a saber: desplegar columnas en un rotativo londinense de gran tirada..., lo consigue un torero: Machaquito. El tono, procediendo del país pionero de las sociedades protectoras de animales, es adivinable: nuestro héroe deviene en «matarife» y la fiesta en «pasatiempo de cobardes» en el que destaca su «crueldad increíble, fantástica, diabólica... ». «Un artículo más contra los toros» parece concluir Araquistáin, sin embargo, la crítica británica le da pie para establecer que «la sensibilidad española -y con esto ocurre lo mismo que con todos los elementos integrantes del pueblo español-, no ha alcanzado todavía el grado de humanización de la sensibilidad media de Europa» ${ }^{51}$.

Más allá del análisis del fabianismo de nuestro autor, la corresponsalía londinense nos pone en la pista del abandono de anteriores querencias ideológicas: «Como filosofía, el anarquismo me parece una doctrina absurda» afirma, aunque a renglón seguido se muestre preocupado con la posibilidad del reforzamiento de las leyes de inmigración británicas para impedir la entrada de anarquistas extranjeros. Confía en los liberales ingleses, «cuya firmeza cerebral sabrá resistir esta ola de odio y miedo con que han inundado sus periódicos los enemigos de las libertades públicas» ${ }^{52}$. En otros momentos se muestra más condescendiente y, de manera sorprendente, se desmarca conceptuando al anarquismo como «la forma más cándida del liberalismo ${ }^{53}$.

De su breve activismo sindicalista en tierras australes guardará una impronta precisa y, por ejemplo, apoyará las huelgas ferroviarias británicas del verano de 1910. Se trataba -afirma- de «alzarse contra la conducta abusiva de los jefes de último orden ${ }^{54}$, puesto que está convencido de que las huelgas no derivan de la exacta compresión por parte de los obreros de las «relaciones que median entre el capital y el trabajo», sino que simplemente protestan contra el abuso de autoridad de los jefes inmediatamente superiores. En otros momentos hará un concienzudo análisis económico de los puntos a favor y en contra del establecimiento por ley de un salario mínimo ${ }^{55}$, elogiará la amplitud de gama que muestra el asociacionismo de los obreros industriales y los agrarios ${ }^{56}$, o cuando nuevamente las huelgas ferroviarias asolen los principales núcleos industriales británicos en el verano de 1911, se detendrá a reflexionar desde posiciones más realistas, «toda solución a todo conflicto social, dentro de nuestro régimen, es transitoria $»^{57}$, y exigirá la aplicación de su particular combinación de igualitarismo y competitividad, aquí de nuevo en clave fabiana: «No se pide que todos sean iguales, sino que en la carrera emocionante de la vida todos arranquen de la misma raya y por el mismo camino, y que cada uno haga el recorrido que pueda» ${ }^{58}$.

51. L. Araquistáin, “Machaquito en Inglaterra”, El Liberal, Madrid, 3 de junio de 1911, 2.

52. L. Araquistáin, "Persecución de anarquistas", El Liberal, Madrid, 9 de enero de 1911, 2.

53. L. Araquistáin, "Los socialistas japoneses", El Liberal, Madrid, 23 de enero de 1911, 1.

54. L. Araquistáin, "En huelga”, El Liberal, Madrid, 26 de julio de 1910, 2.

55. Véase, L. Araquistáin, "El salario mínimo", El Liberal, Madrid, 3 de mayo de 1911, 2.

56. Véase, L. Araquistáin, "Política y agricultura", El Liberal, Madrid, 30 de julio de 1911, 1.

57. Véase, L. Araquistáin, "Las causas del conflicto", El Liberal, Madrid, 21 de agosto de 1911, 1; y "Quién derrotó a los patronos", El Liberal, Madrid, 24 de agosto de 1911, 1.

58. Araquistáin, "Las causas del conflicto", loc. cit., 1. 


\section{5.- Conclusiones}

La actividad del joven Araquistáin como corresponsal londinense del periódico madrileño El Liberal, a lo largo de 1911, nos descubre los primeros pasos formativos en los que se forja una personalidad intelectual que atravesará diferentes etapas a lo largo de su dilatada vida política; como señala Antonio Rivera, hay muchos Araquistáin, pero todas sus etapas vitales e intelectuales no pueden interpretarse de manera estanca, impermeabilizadas unas de otras, al contrario, hay muchas continuidades entre ellas ${ }^{59}$. Este primer Araquistáin, joven periodista en tierras británicas, se aproxima al socialismo fabiano del que obtiene la decantación de elementos muy importantes con un doble alcance: primero, son elementos que se incorporan al corpus ideológico de la Generación del 14 y, segundo, configuran las bases de su futura aliadofilia que desempeñará desde las páginas del semanario España. Esos elementos son fundamentalmente: la pedagogía política entendida como pedagogía sobre la opinión pública, limitado sentido intervencionista del Estado, función activa de las elites políticas, sentido moralizante de la actividad pública y papel relevante de la cultura como motora de la educación política de la ciudadanía. Todos estos elementos se encuentran claramente perfilados a la altura de 1911.

59. A. Rivera García, "Regeneracionismo, socialismo y escepticismo en Luis Araquistáin", Arbor, septiembre-octubre, 729, 2009, 1019. 